\title{
Lack of correlation between bronchoconstrictor response and bronchodilator response in a population-based study
}

\author{
W.R. Douma*, A. de Gooijer**, B. Rijcken+, J.P. Schouten+, G.H. Koëter*, \\ S.T. Weiss $\stackrel{+\neq}{+\neq}$, D.S. Postma*
}

Lack of correlation between bronchoconstrictor response and bronchodilator response in a population-based study. W.R. Douma, A. de Gooijer, B. Rijcken, J.P. Schouten, G.H. Koëter, S.T. Weiss, D.S. Postma. (OERS Journals Ltd 1997.

ABSTRACT: Bronchodilator and bronchoconstrictor responsiveness have been considered physiological opposites in patients with obstructive airways disease. Provocation challenges have been replaced by bronchodilator tests in the assessment of cases of severe airways obstruction. The aim of this study was to examine the relationship between bronchoconstrictor and bronchodilator responsiveness, and their supposed interchangeability, in a general population.

From the Vlagtwedde-Vlaardingen follow-up study, 101 adults were recruited (mean (sD) age 55 (11) yrs, 67 males and 34 females, and 31 were smokers). All completed a questionnaire on airways symptoms. Bronchoconstrictor and bronchodilator responsiveness were assessed with cumulative dose-response curves, using histamine and terbutaline, respectively. Thus, it was possible to relate histamine sensitivity of the airways (the concentration of histamine, at which forced expiratory volume in one second (FEV1) falls by $10 \%$ (PC10)) to the maximal bronchodilator response ( $\triangle$ FEV1) and the sensitivity to the bronchodilator (cumulative dose of inhaled terbutaline at which FEV1 increases by $10 \%$ (RD10)).

Subjects with a bronchoconstrictor response (PC10 $\left.ð 16 \mathrm{mg} \cdot \mathrm{mL}^{-1} ; \mathrm{n}=38\right)$ had more respiratory symptoms than those without $(n=63)(40$ versus $21 \%)$ and also lower baseline FEV1 values (90 versus $96 \%$ predicted), but had comparable bronchodilator responsiveness. Subjects with a bronchodilator response $\left(\triangle \mathrm{FEV} 1 \mathrm{~S}^{\mathrm{S}} \mathbf{2 \%}\right.$ of the predicted value; $n=13$ ) did not differ from those without $(n=88)$ for all parameters, including symptoms, allergy and pulmonary function. In those with a bronchoconstrictor response, there was a weak but significant correlation between the PC10 and RD10 (rho= -0.32), but not between PC10 and $\triangle F E V 1$.

This study suggests that bronchoconstrictor and bronchodilator responsiveness are not highly correlated, even in subjects with airways obstruction. Symptoms were associated with the presence of a bronchoconstrictor, but not a bronchodilator, response. We conclude that bronchoconstrictor and bronchodilator responsiveness are two different phenotypic markers that are not interchangeable in epidemiological studies. Eur Respir J 1997; 10: 2772-2777.
*Dept of Pulmonology, University Hospital, Groningen, The Netherlands. **Dept of Internal Medicine, Academisch Ziekenhuis Vrije Universiteit, Amsterdam, The Netherlands. ${ }^{+}$Dept of Epidemiology, University of Groningen, Groningen, The Netherlands. Fhanning Laboratory, Dept of Medicine, Brigham and Women's Hospital, Harvard Medical School, Boston, USA. \#Pulmonary and Critical Care Division, Dept of Medicine, Beth Israel Hospital, Harvard Medical School, Boston, USA.

Correspondence: D.S. Postma

University Hospital Groningen

Dept of Pulmonology

Hanzeplein 1

9713 GZ Groningen

The Netherlands

Keywords: Bronchial hyperresponsiveness epidemiology

reversibility

Received: October 281996

Accepted for publication August 11997
Bronchoconstrictor responsiveness, airways obstruction, and bronchodilator responsiveness are three main features of asthma and chronic obstructive pulmonary disease (COPD) [1-5]. Asthma is generally characterized by increased airways responsiveness to a bronchoconstrictor, variable airways obstruction, and a significant response to a bronchodilator; whereas, COPD is associated with airways obstruction, a small response or a lack of response to a bronchodilator, and, frequently, increased airways responsiveness to a bronchoconstrictor.

Both bronchoconstrictor and bronchodilator tests have been used to evaluate airways responsiveness [6-10]. Bronchodilator responsiveness has been considered to be the physiological opposite of bronchoconstrictor responsiveness, and provocation challenges with a bronchoconstrictor, when contraindicated for severe airways obstruction, have been replaced by bronchodilator tests. Although a large number of bronchial provocation tests have been performed in epidemiological studies with a very low frequency of adverse effects, it may be preferable to use a bronchodilator rather than a bronchoconstrictor stimulus because of possible risks of severe airways obstruction and adverse effects with higher doses of bronchoconstrictive agents.

The aim of the present study was to examine the relationship between bronchoconstrictor and bronchodilator responsiveness and their supposed interchangeability in a general population. Bronchoconstrictor responsiveness is usually tested with dose-response curves and bronchodilator responsiveness with a single dose of the drug; thus, these tests of change in airway diameter are not performed in an identical manner for each stimulus. In this study, we assessed the responsiveness to both stimuli with doseresponse curves, relating the bronchoconstrictor sensitivity 
of the airways not only to the maximal bronchodilator response but also to the sensitivity to the bronchodilator. Finally, we evaluated the dose needed to obtain the maximal bronchodilator response in a general population.

\section{Methods}

The current analysis concerns data from the Vlagtwedde/Vlaardingen Study, a cohort study of risk factors for the development of COPD $[9,11,12]$. At Vlaardingen, the initial cohort consisted of 859 subjects (aged 40-54 yrs) who were seen in 1965, and of 1,590 subjects (aged 15-39 yrs) seen in 1969. From 1972 onwards, this cohort was seen for follow-up every 3 yrs. Histamine responsiveness was measured in a random sample of $25 \%$ in the first and second surveys. Those subjects who had performed a challenge test in one of the preceding surveys were challenged in later surveys. A random sample of subjects not previously tested was added if time permitted.

During this survey, there were 800 participants. In 51 subjects, no technically satisfactory tracing was obtained, and 7 male and 9 female subjects had a forced expiratory volume in one second (FEV1) value less than $1.5 \mathrm{~L}$. These have all been excluded from bronchial provocation testing. Of the remaining subjects, 319 were selected to perform a histamine challenge test. During the first four of the five study days, all subjects who underwent a histamine challenge test were asked to return the next day for bronchodilator testing. For logistic reasons, a limited number of 101 subjects could be tested.

\section{Questionnaire}

Trained interviewers collected data on age, gender, smoking habits and respiratory symptoms by means of a Dutch version of the British Medical Research Council's standard questionnaire [13]. Subjects were considered symptomatic if they had one or more of the following six symptoms: 1) chronic cough or 2) chronic phlegm, defined as cough or phlegm production on most days or nights for at least three consecutive months during the winter of at least two consecutive years; 3 ) episodes of bronchitis, defined as a period of at least 3 weeks with (increased) cough and phlegm in the past 3 yrs; 4) dyspnoea of grade III or more, defined as shortness of breath when walking with other persons of a similar age on level ground; 5) current persistent wheeze, defined as a wheezing or whistling sound in the chest during most days or nights; and 6) asthmatic attacks, i.e. attacks of shortness of breath with wheezing. Current smokers were defined as individuals who reported smoking at least one cigarette per day during the last year.

\section{Pulmonary function testing}

A water-sealed spirometer (Lode Spirograph D53; Lode Instruments, Groningen, The Netherlands) was used for measurements of pulmonary function. Inspiratory vital capacity (IVC) and FEV1 were assessed in one manoeuvre. At least two technically satisfactory manoeuvres were completed; the difference between two IVC values had to be less than $150 \mathrm{~mL}$, and between two FEV1 values less than $100 \mathrm{~mL}$. The higher value in each category was taken as baseline (according to the criteria of the American Thoracic Society). Bronchodilators were not used for at least $8 \mathrm{~h}$ before all tests of pulmonary function. Use of $\beta$-blockers was considered a contra-indication for pulmonary function testing.

\section{Histamine challenge test}

Subjects inhaled aerosols of histamine biphosphate in doubling concentrations ranging $1-32 \mathrm{mg} \cdot \mathrm{mL}^{-1}$ for $30 \mathrm{~s}$, until the FEV1 decreased more than $20 \%$ from baseline. IVC and FEV1 manoeuvres were performed 30 and $90 \mathrm{~s}$ after each challenge. The provocative concentration of histamine causing a $10 \%$ fall in FEV 1 from baseline (PC10) was calculated. A PC10 of $ð 16 \mathrm{mg} \cdot \mathrm{mL}^{-1}$ was considered to represent a bronchoconstrictor response [9]. A PC10 ð16 mg.mL-1 corresponds to a PC20 ð32 $\mathrm{mg} \cdot \mathrm{mL}^{-1}$, which is generally considered to be in the asthmatic range.

\section{Bronchodilator test}

The response to the bronchodilator was assessed 1 day after the histamine challenge test. Once again, bronchodilators were not used for at least $8 \mathrm{~h}$ before testing. After the determination of baseline IVC and FEV1 values, subjects inhaled terbutaline from a dose aerosol using a spacing device (Spacer®; Astra-Draco, Lund, Sweden) in cumulative doubling doses of $30-2,000 \mu \mathrm{g}$ at $5 \mathrm{~min}$ intervals. To obtain these cumulative doubling doses, two different doses of inhaled terbutaline were used, 30 and $250 \mu \mathrm{g} \cdot$ puff $^{-1}$. A plateau in bronchodilation was considered to have been reached if the FEV1 increased by $<5 \%$ during three consecutive doubling doses. The test was terminated if the FEV1 did not increase by $>5 \%$ during three consecutive doubling-doses; however, in no case was it terminated before a cumulative dose of at least $240 \mu \mathrm{g}$ terbutaline had been administered. The cumulative dose of terbutaline causing a $10 \%$ improvement in FEV1 from baseline (RD10) was calculated. Maximal airways response to terbutaline was expressed as percentage from the baseline value $(\triangle \mathrm{FEV} 1 \%$ BL) or as percentage from the predicted value of FEV1 ( $\triangle \mathrm{FEV} 1 \%$ pred), which is less dependent on baseline FEV 1 . The presence of a bronchodilator response was defined by a $\triangle \mathrm{FEV} 1$ of $\breve{S} 9 \%$ pred [14].

\section{Allergy parameters}

Serum immunoglobulin E ( $\operatorname{IgE}$ ) was determined by the CAP-system fluorescence enzyme immunoassay (FEIA) (Pharmacia, Uppsala, Sweden). Absolute peripheral blood eosinophil counts were determined with a Technicon-H1 blood cell counter (Bayer AG, Leverkusen, Germany). A set of six aeroallergens (Soluprick and ALK-Lancet, obtained from ALK Benelux, Woerden, The Netherlands) was applied, with the solvent for the allergens (50\% glycerol $/ 50 \%$ aqueous isotone) as a negative control and histamine dihydrochloride solution $\left(3 \mathrm{mg} \cdot \mathrm{mL}^{-1}\right)$ as a positive control [15]. The allergens used were: house dust mite (Dermatophagoides pteronyssinus), mixed grass pollen 
(meadow foxtail, cocksfoot, meadow fescue, rye grass, and timothy), mixed tree pollen (alder, birch and hazel), dog epithelium, cat epithelium and mould (Aspergillus fumigatus). Fifteen minutes after application, the mean wheal diameter (MWD) was calculated as the mean of the largest diameter and the diameter at the midpoint perpendicular to the larger diameter. The size of the MWD was scored from 0 to 5 as follows: $(\partial 5 \mathrm{~mm}=0 ; 5-7.5 \mathrm{~mm}=1$; $7.5-10 \mathrm{~mm}=2 ; 10-12.5 \mathrm{~mm}=3 ; 12.5-15 \mathrm{~mm}=4$; and $>15$ $\mathrm{mm}=5$ ). Allergy was defined as a total score of $\breve{S} 1$.

\section{Data analysis}

All analyses were performed with the SPSS PC statistical package (SPSS Inc., Chicago, IL, USA) package. The Chi-squared and Fisher's exact tests were used for analyses of dichotomous variables. The normality of the distributions of continuous variables was examined in the Kolmogorov/Smirnov test. In case of non-normality (a p-value of less than 0.05), nonparametric techniques were used (Mann-Whitney U-test); otherwise, parametric tests were employed (Student's t-test). Correlation coefficients were estimated by Spearman rank correlation. Values for total $\operatorname{IgE}$ and eosinophil counts were log-transformed before all analyses.

\section{Results}

Of the 326 subjects who underwent a histamine challenge test, 101 also performed a bronchodilator test. This subgroup did not differ from the group who did not per- form a bronchodilator test in terms of the following variables: age; proportion of males; IgE level; number of eosinophils; proportion with positive skin-prick tests; smoking habits; symptoms; FEV1; and increased airways responsiveness to histamine. The mean age (SD) of the 101 participants was 55 (10) yrs; 66\% were male. Thirty eight of the participants had a bronchoconstrictor response (cut-off value: PC10 ð16 $\mathrm{mg} \cdot \mathrm{mL}^{-1}$ ), 39\% had obstructed airways (cut-off value: FEV1, ð85\% pred), and $13 \%$ a bronchodilator response (cut-off value: $\triangle \mathrm{FEV} 1 \mathrm{~S} 9 \%$ pred) [14]. Only two patients had an increase in FEV1 of $\mathrm{S} 15 \%$ relative to the initial value.

Table 1 (left columns) shows that patients with a bronchoconstrictor response had significantly more respiratory symptoms and lower baseline FEV1 (\% pred) than those without a bronchoconstrictor response. No significant difference was found in the mean levels of bronchodilator responsiveness between the two groups; moreover, the proportions of subjects with a bronchodilator response were similar, even when the bronchodilator response was expressed as an improvement of $\mathrm{S} 10 \%$ from the baseline value.

When subjects with and without a bronchodilator response were compared (table 1, right columns), no statistically significant differences were evident, including the mean level of bronchoconstrictor responsiveness and the percentage of subjects with a bronchoconstrictor response. Using an FEV1 of Š10\% BL as the cut-off value for bronchodilator responsiveness did not change these results.

The proportional Venn diagram (fig. 1) was constructed to represent the 101 participants. The subjects were divided

Table 1. - Characteristics of the 101 participants of a population-based study by bronchoconstrictor response and by bronchodilator response

\begin{tabular}{|c|c|c|c|c|c|c|c|c|c|}
\hline \multirow[b]{3}{*}{ Male } & \multicolumn{4}{|c|}{ Bronchoconstrictor response } & & \multicolumn{4}{|c|}{ Bronchodilator response } \\
\hline & \multicolumn{2}{|c|}{$\begin{array}{c}\mathrm{PC} 10>16 \mathrm{mg} \cdot \mathrm{mL}^{-1} \\
(\mathrm{n}=63)\end{array}$} & \multicolumn{2}{|c|}{$\begin{array}{c}\text { PC10 ð16 mg.mL } \mathrm{mL}^{-1} \\
(\mathrm{n}=38)\end{array}$} & & \multicolumn{2}{|c|}{$\begin{array}{c}\Delta \mathrm{FEV}_{1}<9 \% \text { pred } \\
(\mathrm{n}=88)\end{array}$} & \multicolumn{2}{|c|}{$\begin{array}{c}\Delta \mathrm{FEV}_{1} \text { Š9\% pred } \\
(\mathrm{n}=13)\end{array}$} \\
\hline & 46 & (73) & 21 & $(55)$ & & 60 & (68) & 7 & $(54)$ \\
\hline Positive skin-prick test & 7 & (1) & 6 & (16) & & 11 & (13) & 2 & (18) \\
\hline 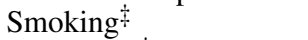 & 19 & (30) & 12 & (32) & & 29 & (33) & 2 & (15) \\
\hline \multicolumn{10}{|l|}{ Symptoms } \\
\hline Dyspnoea gradeŠIIII & 3 & (5) & 3 & (8) & & 5 & (6) & 1 & (8) \\
\hline Chronic cough & 5 & (8) & 8 & (21) & & 12 & (14) & 1 & (8) \\
\hline Chronic phlegm & 2 & $(3)^{*}$ & 9 & (24) & & 10 & (11) & 1 & (8) \\
\hline Bronchitis episodes & 7 & (11) & 7 & (18) & & 12 & (14) & 2 & (17) \\
\hline Persistent wheeze & 0 & $(0)^{*}$ & 4 & (11) & & 4 & (5) & 0 & \\
\hline Asthma attacks & 1 & (2) & 1 & (3) & & 1 & (1) & 1 & (8) \\
\hline Any symptoms & 13 & $(21)^{*}$ & 15 & (40) & & 26 & (30) & 2 & (17) \\
\hline Dyspnoea grade ŠII & 7 & $(11)^{*}$ & 14 & (37) & & 18 & (21) & 3 & (23) \\
\hline Age yrs $\#$ & 54 & (12) & 56 & (11) & & 54 & $(11)$ & 57 & (12) \\
\hline $\log _{10} \operatorname{IgE} \mathrm{IU}^{\#}$ & 1.52 & $(0.51)$ & 1.54 & (0.61) & & 1.52 & $(0.57)$ & 1.58 & $(0.38)$ \\
\hline $\log _{10} \operatorname{eos} \cdot \mathrm{mm}^{-3 \#}$ & 1.11 & $(0.28)$ & 1.16 & $(0.23)$ & & 1.12 & $(0.26)$ & 1.22 & $(0.23)$ \\
\hline FEV1 day $1 \%$ pred $^{\#}$ & 96 & $(12)^{*}$ & 90 & $(15)$ & & 94 & $(13)$ & \multicolumn{2}{|c|}{$92 \quad(20)$} \\
\hline FEV1 day $2 \%$ pred $^{\#}$ & 94 & $(12)^{*}$ & 87 & (15) & \multirow{5}{*}{$\begin{array}{l}\text { PC10 } 16 \mathrm{mg} \cdot \mathrm{mL}^{-1 \dagger} \\
\log _{2} \mathrm{PC} 10 \mathrm{mg}^{-1} \mathrm{~mL}^{-1 \#} \\
\mathrm{GM} \mathrm{mg} \cdot \mathrm{mL}^{-1}\end{array}$} & 92 & (13) & 88 & (16) \\
\hline$\Delta$ FEV1 Š $9 \%$ pred & 8 & (13) & 5 & (13) & & 33 & (38) & 5 & (38) \\
\hline$\Delta \mathrm{FEV}_{1} \mathrm{~S} 10 \% \mathrm{BL}^{\ddagger}$ & 10 & (16) & 5 & (13) & & \multirow{3}{*}{$\begin{array}{r}53 \\
4.2 \\
18.9\end{array}$} & \multirow[t]{3}{*}{$(1.9)$} & \multirow{3}{*}{$\begin{array}{r}4.0 \\
15.9\end{array}$} & $(2.5)$ \\
\hline$\Delta \mathrm{FEV}_{1} \%$ pred $^{\#}$ & 4.1 & (3.5) & 5.1 & (3.3) & & & & & \\
\hline$\Delta \mathrm{FEV}_{1} \% \mathrm{BL}^{\#}$ & 4.6 & $(4.1)$ & 6.0 & $(4.1)$ & & & & & \\
\hline
\end{tabular}

Values are presented as: ness of breath when walking quickly on level ground, or up the stairs, or up a slope; dyspnoea grade ŠIII: shortness of breath when walking with other persons of their own age on level ground. IgE: immunoglobulin E; FEV1: forced expiratory volume in one second; $\%$ pred: percentage of predicted value; \% BL: percentage of baseline value; eos: eosinophils; PC10: concentration of histamine causing a $10 \%$ fall in FEV1; $\triangle F^{2} V_{1}$ : maximal increase in FEV1 after inhaled terbutaline; GM: geometric mean. *: p<0.05 comparing bronchoconstrictor response with no bronchoconstrictor response and bronchodilator response with no bronchodilator response. 
into groups with a bronchoconstrictor response (PC10 ð16 $\left.\mathrm{mg} \cdot \mathrm{mL}^{-1}\right)$ and/or a bronchodilator response $(\triangle \mathrm{FEV} 1 \mathrm{\textrm {S }} 9 \%$ pred) and/or airways obstruction (FEV1 ð85\% pred). The percentages of subjects with a bronchodilator resp-onse were the same in the groups with and without a bron-choconstrictor response $(13 \%)$, the percentages of subjects with a bronchoconstrictor response were comparable in the groups with and without a bronchodilator response (39 and $38 \%$, respectively). Of the group with airways obstruction, $46 \%$ exhibited a bronchoconstrictor response and $15 \%$ displayed a bronchodilator response. When only the 39 subjects with airways obstruction (FEV1 ð85\% pred) were considered, the percentages of subjects with a bronchodilator response in the groups with and without a bronchoconstrictor response were comparable (17 and 14\%, respectively); the same was true for the percentages of subjects with a bronchoconstrictor response in the groups with and without a bronchodilator response (50 and $45 \%$, respectively). Therefore, even in the case of airways obstruction, subjects with a bronchodilator response were not more likely to exhibit a bronchoconstrictor response and subjects with a bronchoconstrictor response were not more likely to display a bronchodilator response.

Table 2 shows the correlation matrix of different parameters of pulmonary function for all 101 subjects and for four subgroups: 1) subjects with a bronchodilator response ( $\triangle \mathrm{FEV} 1 \mathrm{~S} 9 \%$ pred); 2) subjects with a bronchodilator response $(\triangle \mathrm{FEV} 1 \breve{S} 10 \% \mathrm{BL}) ; 3)$ subjects with a bronchoconstrictor response (PC10 ð16 $\mathrm{mg} \cdot \mathrm{mL}^{-1}$ ); and 4) subjects with airways obstruction (FEV1 $885 \%$ pred).

$\log _{2}$ PC10 was significantly correlated with FEV1\% pred in the whole group (rho=0.26), as well as in the subgroups with airways obstruction and a bronchoconstrictor response. This correlation was highest in subjects with a bronchoconstrictor response (rho=0.64). As expected, when expressed as a percentage of the baseline value, bronchodilator responsiveness was significantly correlated with baseline FEV1 (rho=0.25); when expressed as a percentage of the predicted value, it was not. The latter correlation was highest $(\mathrm{rho}=-0.84)$ in patients with a bronchodilator response ( $\triangle \mathrm{FEV} 1 \mathrm{~S} 9 \%$ pred). Bronchoconstrictor respon-

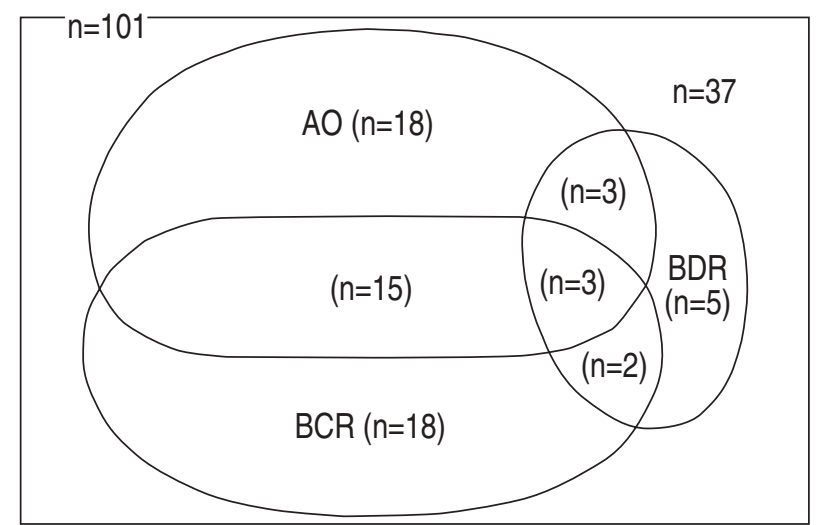

Fig. 1. - Proportional Venn-diagram of the 101 participants of a population-based study representing the prevalence of bronchodilator and bronchoconstrictor responsiveness (BDR and BCR, respectively) and airways obstruction. BCR PC10 $16 \mathrm{mg} \cdot \mathrm{mL}^{-1}(\mathrm{n}=38)$; BDR $\triangle \mathrm{FEV}_{1} \mathrm{~S} 9 \%$ pred $(\mathrm{n}=13)$; AO: airways obstruction $\left(\mathrm{FEV}_{1}\right.$ ð85\% pred) $(\mathrm{n}=39) ; \mathrm{PC} 10$ : provocative concentration of histamine causing a $10 \%$ fall in forced expiratory volume in one second $\left(\mathrm{FEV}_{1}\right) ; \triangle \mathrm{FEV}_{1}$ : maximal increase in FEV $1 ; \%$ pred: percentage of predicted value.
Table 2. - Correlation coefficients (Spearman rho) for different pulmonary function parameters and bronchoconstrictor responsiveness in all participants and in subgroups of participants with bronchodilator or bronchoconstrictor responsiveness, or with airways obstruction

\begin{tabular}{|c|c|c|c|c|c|}
\hline & & $\begin{array}{c}\text { FEV } 1 \%^{\%} \\
\text { pred }\end{array}$ & $\begin{array}{l}\Delta \text { FEV1 } \\
\% \text { pred }\end{array}$ & $\begin{array}{c}\Delta \mathrm{FEV} 1 \\
\% \mathrm{BL}\end{array}$ & $\begin{array}{l}\log _{2} \\
\text { RD10 }\end{array}$ \\
\hline $\begin{array}{l}\text { Total } \\
(\mathrm{n}=101)\end{array}$ & $\begin{array}{l}\log _{2} \mathrm{PC}_{10} \\
\log _{2} \mathrm{RD} 10 \\
\Delta \mathrm{FEV} 1 \% \text { pred } \\
\Delta \mathrm{FEV} 1 \% \mathrm{BL}\end{array}$ & $\begin{array}{l}0.262 * \\
0.257 * \\
-0.092 \\
-0.249 *\end{array}$ & $\begin{array}{l}-0.113 \\
-0.596\end{array}$ & $\begin{array}{l}-0.169 * \\
-0.615\end{array}$ & -0.030 \\
\hline $\begin{array}{l}\Delta \mathrm{FEV} 1 \\
\text { Š9\% pred } \\
(\mathrm{n}=13)^{+}\end{array}$ & $\begin{array}{l}\log _{2} \mathrm{PC} 10 \\
\log _{2} \mathrm{RD} 10 \\
\Delta \mathrm{FEV} 1 \% \text { pred } \\
\Delta \mathrm{FEV} 1 \% \mathrm{BL}\end{array}$ & $\begin{array}{c}0.425 \\
0.393 \\
-0.066 \\
-0.841 *\end{array}$ & $\begin{array}{l}-0.142 \\
-0.369\end{array}$ & $\begin{array}{l}-0.465 \\
-0.548^{*}\end{array}$ & 0.227 \\
\hline $\begin{array}{l}\Delta \mathrm{FEV} 1^{+} \\
\text {S } 10 \% \mathrm{BL} \\
(\mathrm{n}=15)^{+}\end{array}$ & $\begin{array}{l}\log _{2} \mathrm{PC}_{10} \\
\log _{2} \mathrm{RD} 10 \\
\Delta \mathrm{FEV} 1 \% \text { pred } \\
\Delta \mathrm{FEV} 1 \% \mathrm{BL}\end{array}$ & $\begin{array}{r}0.370 \\
-0.093 \\
0.368 \\
-0.439\end{array}$ & $\begin{array}{l}-0.188 \\
-0.514 *\end{array}$ & $\begin{array}{l}-0.416 \\
-0.361\end{array}$ & 0.418 \\
\hline $\begin{array}{l}\mathrm{PC} 10 \text { ð16 } \\
\mathrm{mg} \cdot \mathrm{mL}^{-1} \\
(\mathrm{n}=38)^{\dagger}\end{array}$ & $\begin{array}{l}\log _{2} \mathrm{PC}_{10} \\
\log _{2} \mathrm{RD} 10 \\
\Delta \mathrm{FEV} 1 \% \text { pred } \\
\Delta \mathrm{FEV} 1 \% \mathrm{BL}\end{array}$ & $\begin{array}{l}0.641 * \\
0.218 \\
0.084 \\
-0.151\end{array}$ & $\begin{array}{c}0.038 \\
-0.559 *\end{array}$ & $\begin{array}{l}-0.105 \\
-0.586^{*}\end{array}$ & $0.312^{*}$ \\
\hline $\begin{array}{l}\text { Baseline } \\
\text { FEV } 1 \\
\text { ð85\% pred } \\
(\mathrm{n}=39)^{+}\end{array}$ & $\begin{array}{l}\log _{2} \mathrm{PC}_{10} \\
\log _{2} \mathrm{RD} 10 \\
\Delta \mathrm{FEV} 1 \% \text { pred } \\
\Delta \mathrm{FEV} 1 \% \mathrm{BL}\end{array}$ & $\begin{array}{l}0.354^{*} \\
0.165 \\
-0.224 \\
-0.336^{*}\end{array}$ & $\begin{array}{l}-0.087 \\
-0.756^{*}\end{array}$ & $\begin{array}{l}-0.136 \\
-0.761 *\end{array}$ & 0.030 \\
\hline
\end{tabular}

RD10: cumulative dose of inhaled terbutaline at which FEV1 increases by $10 \%{ }^{+}+$: bronchodilator response; $\dagger^{\dagger}$ : bronchoconstrictor response. For further definitions see legend to table $1 . *$ : $\mathrm{p}<0.05$.

siveness was significantly correlated with bronchodilator responsiveness only when expressed as a $\triangle F E V 1$ of Š10\% $\mathrm{BL}$, but this correlation was very weak $(\mathrm{rho}=-0.17)$. In subjects with a bronchoconstrictor resp-onse, the correlation with bronchodilator responsiveness was higher (rho= 0.31 ), but only when expressed as $\log _{2}$ RD10.

The maximal response to terbutaline was reached after a cumulative dose of $240 \mu \mathrm{g}$ in one subject, and after a dose of $120 \mu \mathrm{g}$ in 10 subjects; 90 subjects reached a plateau after a dose of $60 \mu \mathrm{g}$ or had no increase in FEV1 of Š5\% during the test.

\section{Discussion}

This population-based study suggests that bronchoconstrictor responsiveness and bronchodilator responsiveness as reflected by $\triangle \mathrm{FEV} 1$ and/or RD10 are not identical, even in subjects with airways obstruction. Furthermore, the results indicate that the outcome of a bronchodilator test is not an accurate basis for the classification of a person as having increased airways responsiveness to bronchoconstrictor agents or not, in epidemiological research. In subjects with a bronchoconstrictor response, $\mathrm{PC} 10$ and $\mathrm{RD} 10$ were significantly positively correlated, but $\mathrm{PC} 10$ and the level of airway dilation were not. Finally, cumulative bronchodilator testing provided a maximal FEV1 value, with a dose of $500 \mu \mathrm{g}$ of terbutaline or less.

It has been suggested that bronchodilator responsiveness is the physiological opposite of bronchoconstrictor responsiveness, and, therefore, that challenge tests with doubling concentrations of a bronchoconstrictor can be 
replaced by bronchodilator tests in subjects with airways obstruction. For example, Woolcock et al. [16] used the outcome of a bronchodilator test in subjects with severe airways obstruction (FEV1 ð 60\% pred) to classify subjects as having increased airways responsiveness to a bronchoconstrictor. The idea that the tests are interchangeable seems reasonable because bronchoconstrictor responsiveness and bronchodilator responsiveness do have several features in common. Firstly, both responses are characterized by changes in bronchial smooth muscle tone. Secondly, the severity of bronchoconstrictor responsiveness [17] and the extent of bronchodilator responsiveness (especially when expressed as a percentage of baseline FEV1) [14] are both dependent on the level of airways obstruction. Patients with more severe airways obstruction are more sensitive to a bronchoconstrictor and respond better to a bronchodilator. In 1978, Benson [18] found a significant positive correlation between the size of the constrictor response to histamine and the dilator response to isoprenaline in 19 patients with asthma. asthmatic bronchitis and chronic bronchitis. From the results, it can be seen that patients with asthma showed greater bronchial reactivity both to histamine and isoprenaline than those with asthmatic bronchitis or chronic bronchitis. However, the significant correlation between bronchodilator and bronchoconstrictor response was due to the fact that all three groups were taken in the analysis. In the group with asthmatics only, no significant correlation would have been found. Thirdly, both bronchoconstrictor and bronchodilator responsiveness are independent predictors of the response to treatment with inhaled corticosteroids. Bronchoconstrictor responsiveness is predictive of improvement in FEV1 within 3 months of the initiation of treatment with inhaled steroids, whereas bronchodilator responsiveness is predictive of a more favourable longterm pattern of FEV1 in patients with asthma and COPD [19].

Although bronchoconstrictor responsiveness and bronchodilator responsiveness have features in common, there is also evidence that they are not identical. Allergic asthmatics can have a normal baseline FEV1, with no bronchodilator response but with increased airways responsiveness to a bronchoconstrictor. Furthermore, patients with COPD and severe airways obstruction can respond to histamine or methacholine challenge with a decrease in FEV1, without any increase in FEV1 after bronchodilator therapy. Bronchoconstrictor responsiveness and bronchodilator responsiveness are independent prognostic factors in COPD patients, but in the opposite direction. The more responsive to a bronchodilator and the less responsive to a bronchoconstrictor, the less FEV1 declines in long-term studies [20-22].

These findings pertain to patients with established airways disease. However, the relationship between bronchoconstrictor and bronchodilator responsiveness has not been formally investigated in an epidemiological setting.

The present data suggest that bronchodilator responsiveness is not the physiological opposite of bronchoconstrictor responsiveness. The data presented in table 1 show no differences between subjects with and without a bronchoconstrictor response either in the prevalence or the level of bronchodilator responsiveness. Moreover, subjects with a bronchodilator response did not differ from those without in terms of the prevalence or the level of bronchoconstrictor responsiveness. Thus, subjects with increased airways responsiveness to histamine were not more likely to exhibit a bronchodilator response, and subjects with a bronchodilator response were not more likely to display increased airways responsiveness to histamine. These findings were independent of the way in which bronchodilator responsiveness was expressed, $(\triangle \mathrm{FEV} 1 \% \mathrm{BL}$ or $\triangle \mathrm{FEV} 1 \%$ pred) and of airways obstruction status. Furthermore, subjects with a bronchoconstrictor response had more respiratory symptoms and a lower baseline FEV $1 \%$ pred than nonresponders. In contrast, subjects with a bronchodilator response were indistinguishable from those without in terms of all of the parameters measured in relation to symptoms, allergy and pulmonary function, although not all specific symptom parameters can be fully interpreted because of the small number of subjects. Thus, bronchodilator responsiveness and bronchoconstrictor responsiveness are not interchangeable in epidemiological studies, even in subjects with airways obstruction.

We are unable to evaluate the accuracy of classifying a subject as having increased airways responsiveness when FEV1 is $<60 \%$ pred and the bronchodilator response is Š15\% above baseline [16], because none of the subjects had such severe airways obstruction and only two individuals showed this level of bronchodilator responsiveness. However, the present data do indicate that a large percentage of subjects without a bronchodilator response (even those with fixed airways obstruction) still have a bronchoconstrictor response. Therefore, it is impossible to classify a person as having no increased airways responsiveness to a bronchoconstrictor based on the absence of a bronchodilator response, also in the presence of airways obstruction.

Bronchoconstrictor responsiveness is usually tested with doubling concentrations of histamine or methacholine; these tests provide information about the sensitivity of the airways, and generally not about the maximal airway narrowing [3]. On the other hand, bronchodilator responsiveness is usually tested after a single dose of a bronchodilator ( $\beta_{2}$-agonist or an anticholinergic); these bronchodilator tests provide information about the "maximal" airway dilation, but not about the sensitivity of the airways to the bronchodilator. To compare the interchangeability of both tests formally, it is important to use comparable testing methods that provide the same information. To our knowledge, this is the first epidemiological study in which bronchodilator responsiveness has been measured by means of a cumulative dose-response curve for inhaled terbutaline. With this method, we were able to correlate the sensitivity to histamine (PC10) not only with the maximal airway dilation $(\triangle \mathrm{FEV} 1)$ but also with the sensitivity to terbutaline (RD10).

Our results show that $\mathrm{PC} 10$ was not correlated with RD10 and a $\triangle F E V 1$ of $\breve{S} 9 \%$ of the predicted value in the whole group, and had only a weak correlation with a $\triangle \mathrm{FEV} 1$ of $\mathrm{S} 10 \%$ of the baseline value $(\mathrm{rho}=-0.17)$. One might argue that there is a correlation between bronchoconstrictor response and bronchodilator response in patients with airways obstruction or with bronchoconstrictor responsiveness. However, we did not find this to be the case in the group with FEV1 $ð 85 \%$ pred. Conversely, in subjects with increased airways responsiveness, there was a significant correlation between $\mathrm{PC} 10$ and $\mathrm{RD} 10(\mathrm{rho}=$ 0.312), but not between $\mathrm{PC} 10$ and the level of response to 
a bronchodilator $(\mathrm{rho}=-0.105)$. Thus, in this group, sensitivity to histamine is correlated with sensitivity to terbutaline but not with maximal airways response to terbutaline. In subjects with a bronchodilator response $(\triangle \mathrm{FEV} 1 \mathrm{~S} 10 \%$ $\mathrm{BL})$ the correlation was somewhat higher $(\mathrm{rho}=0.42)$ but did not reach the level of significance, probably due to the small number of subjects $(n=15)$. These results are from a population-based study; it would be intriguing to investigate the relationship between bronchoconstrictor responsiveness and bronchodilator responsiveness with cumulative dose-response curves in patients with asthma.

As a secondary result, our study shows that all subjects reached their maximal response to terbutaline at a cumulative dose of $ð 500 \mu \mathrm{g}$. We therefore suggest that $500 \mu \mathrm{g}$ of terbutaline is sufficient to elicit the maximal airway dilation in cumulative dose-response curves in an epidemiological study.

In summary, cumulative dose-response curves with bronchodilator stimuli appear suitable for epidemiological studies. However, in such studies, bronchoconstrictor and bronchodilator responsiveness are not interchangeable: the absence of bronchodilator responsiveness does not imply the absence of bronchoconstrictor responsiveness, even in individuals with airways obstruction. Further studies must investigate the relationship between bronchoconstrictor responsiveness and bronchodilator responsiveness in subgroups of patients, preferably asthmatics.

Acknowledgments: The authors thank the participants for their co-operation and their colleagues Y. Oosterhoff, E.J.M. Weersink, J.B. Wempe and S. Zuidema for assistance with bronchodilator tests. They thank Astra for delivering the terbutaline canisters.

\section{References}

1. American Thoracic Society. Standards for the diagnosis and care of patients with chronic obstructive pulmonary disease (COPD) and asthma. Am Rev Respir Dis 1987; 136: 225-244.

2. Burrows B. An overview of obstructive lung disease. Med Clin North Am 1981; 65: 455-471.

3. Hargreave FE, Dolovich J, O'Byrne PM, Ramsdale EH, Daniel EE. The origin of airway hyperresponsiveness. $J$ Allergy Clin Immunol 1986; 78: 825-832.

4. Barnes PJ. New concepts in the pathogenesis of bronchial hyperresponsiveness and asthma. J Allergy Clin Immunol 1989; 83: 1013-1026.

5. Woolcock AJ, Anderson SD, Peat JK, et al. Characteristics of bronchial hyperresponsiveness in chronic obstructive pulmonary disease and in asthma. Am Rev Respir Dis 1991; 143: 1438-1443.

6. Taylor SM, Paré PD, Armour CL, Hogg JC, Schellenberg RR. Airway reactivity in chronic obstructive pulmonary disease. Am Rev Respir Dis 1985; 132: 30-35.

7. Taylor RG, Joyce H, Gross E, Holland F, Pride NB. Bronchial reactivity to inhaled histamine and annual rate of decline in FEV 1 in male smokers and ex-smokers. Thorax 1985; 40: 9-16.
8. Cockcroft DW, Berscheid BA, Murdock KY. Unimodal distribution of bronchial responsiveness to inhaled histamine in a random human population. Chest 1983; 83: 751-754.

9. Rijcken B, Schouten JP, Weiss ST, Meinesz AF, Vries K, van der Lende $\mathrm{R}$. The distribution of bronchial responsiveness to histamine in symptomatic and asymptomatic subjects. Am Rev Respir Dis 1989; 140: 615-623.

10. Kanner RE. The relationship between airways responsiveness and chronic airflow obstruction. Chest 1984; 86 : 54-57.

11. van der Lende R. Epidemiology of chronic nonspecific lung disease (chronic bronchitis). Thesis Assen. Royal Van Gorcum 1969.

12. van der Lende R, Kok TJ, Peser R, Quanjer PH, Schouten JP, Orie NGM. Decreases in VC and FEV1 with time: indicators for effects of smoking and air pollution. Bull Eur Physiopathol Respir 1981; 17: 775-792.

13. van der Lende R, Orie NGM. The MRC ECSC questionnaire on respiratory symptoms (use in epidemiology). Scand J Respir Dis 1972; 53: 218-226.

14. Brand PL, Quanjer PH, Postma DS, et al. Interpretation of bronchodilator response in patients with obstructive airways disease: the Dutch Chronic Non-Specific Lung Disease (CNSLD) Study Group. Thorax 1992; 47: 429-436.

15. Mensinga TT, Weiss ST, de Monchy JGR, Schouten JP, Rijcken B, Kauffman HF. Smoking modifies the relationship of markers of allergy to eosinophil count in a community-based population study. Thesis T.T. Mensinga, 1993; Chapter 3; pp. 39-58, Groningen, The Netherlands.

16. Woolcock AJ, Peat JK, Salome CM, et al. Prevalence of bronchial hyperresponsiveness and asthma in a rural adult population. Thorax 1987; 42: 361-368.

17. Rijcken B, Schouten JP, Weiss ST, Speizer FE, van der Lende R. The relationship of nonspecific bronchial responsiveness to respiratory symptoms in a random population sample. Am Rev Respir Dis 1987; 136: 62-68.

18. Benson MK. Bronchial responsiveness to inhaled histamine and isoprenaline in patients with airway obstruction. Thorax 1978; 33: 211-213.

19. Kerstjens HAM, Overbeek SE, Schouten JP, Brand PLP, Postma DS, Dutch CNSLD Study Group. Airways hyperresponsiveness, bronchodilator response, serum IgE, and smoking habit predict improvement in FEV1 during longterm inhaled corticosteroid treatment. Eur Respir J 1993; 6: 868-876.

20. Postma DS, de Vries K, Koëter GH, Sluiter HJ. Independent influence of reversibility of airflow obstruction and nonspecific hyperreactivity on the long-term course of lung function in chronic airflow obstruction. Am Rev Respir Dis 1986; 134: 276-280.

21. Burrows B, Bloom JW, Traver GA, Cline MG. The course and prognosis of different forms of chronic airways obstruction in a sample from the general population. N Engl J Med 1987; 317: 1309-1314.

22. Tashkin DP, Altose DM, Connett JE, Kanner RE, Lee WW, Wise RA, for the Lung Healthy Study Group. Methacholine reactivity predicts changes in lung function over time in smokers with early chronic obstructive pulmonary disease. Am J Respir Crit Care Med 1996; 153: 18021811. 